\title{
Good questions
}

John Launer

I was delighted to learn recently that medical students at Cardiff University have launched a campaign called 'Ask One Question!' They are encouraging their fellow students to ask a single question of every patient they see: "If I could do one thing to improve your stay here today, what would it be?" ${ }^{1}$ As well as showing basic good manners towards patients, the question will help students to develop a patientcentred approach to their work. It will also make students feel useful on the wards, rather than in the way. The organisers are pooling the answers to include in a guide to the top 10 things that all medical students can do to help patients. Apparently the commonest answer to the question is a request for a glass of water, although some answers will doubtless turn out to be of far greater consequence, such as: "I want the doctors to tell me whether I've got cancer". My guess is that some will show up important medical issues, like the fact that a patient is waiting for a crucial test, or there has been an error in their medication.

I have a longstanding interest in the use of questions in medicine, and the effect they have on the quality of medical care. I have always been struck by how we learn so many factual questions in our training - the 'clerking' ones that help you make a diagnosis-and how few of the questions we are taught help us perform all the other tasks that the consultation needs to serve. These tasks include exploring what is on patients' minds, establishing trust, and finding what they actually want from us. Outside the medical profession, people are often taught far more about questioning technique than doctors are. For example, trained mentors and coaches often start each meeting with the question: "What are you hoping to get out of our conversation today?" Asking this can save a lot of time that might otherwise be spent barking up the wrong tree. Using it in medical consultations, I have found the answer is often quite unexpected. People you had assumed were hoping for a prescription only want information or reassurance-and vice versa.

There are several systematic ways of using questions to better effect. The best

Correspondence to Dr John Launer, Faculty Development, Shared Services, Health Education, Stewart House, 32 Russell Square, London WC1B 5DN, UK: john.launer@southlondon.hee.nhs.uk known is probably 'Socratic questioning,' which is a way of helping people to reason out the answers to own their problems, rather than offering the information on a plate. The approach is used a great deal in teaching, but has clinical uses as well. The commonest example is where patients with longstanding problems keep saying that they do not really understand their conditions or treatment. Rather than repeating the same information all over again in the vain hope that it may finally have an impact, gentle Socratic questioning can help people recall how much they really know. Another system of questioning that has become popular in the last few years is 'motivational interviewing.' Increasingly, doctors are using this approach to invite patients to consider the benefits of changes in their life style, and the obstacles that are standing in the way. Like all systems of questioning, it can be used in a mechanical or manipulative manner, but if the doctor has the right attitude and tone of voice, it can be one of the best ways of inspiring people to improve their health.

\section{CIRCULAR QUESTIONS}

For many years, my own preferred style of questioning has been the use of so-called 'circular questions.' The name is unfortunate, because it conveys the impression of going round in circleswhich is exactly the opposite of what the approach is meant to achieve. What 'circular' really means is that you should try to match each of your questions exactly to the words or phrases that each patient uses, so that the questions and answers develop into a continuous loop. This helps people take their stories into the areas that are most important to them, rather than being guided only in the direction that you feel they ought to go in. At its basic level, it can involve questions as simple as 'what do you mean by 'not your usual self'?' With training, you can also use circular questions to invite people to look at their problems from new perspectives: for example 'So when things do get 'really tough' for you, what is it that keeps you going?' The approach was originally developed to help families where someone had a mental health problem. ${ }^{2}$ However, it can have beneficial effects in a wide range of conversations, especially with problems that seem to have got stuck. I have been involved for many years in teaching how to use circular questions both for consultations and for clinical supervision, and helping people learn how to turn medical conversations into a form of therapeutic treatment in its own right. ${ }^{3}$ Although there are some superficial similarities between circular questioning and motivational interviewing, their philosophical underpinnings are very different. Circular questioning starts from the premise that the professional is unlikely to know what is best for patients, and the best way forward will only emerge by allowing their narratives scope to develop under their own momentum, and through genuinely curious inquiry.

As with most clinical skills, you never really stop learning how to ask better questions. For example, I recently attended a seminar led by the US physician Eric Cassell. He has been at the forefront of teaching doctors to move from a view of medicine based on diseased bodies, to one based on altered function. ${ }^{5} \mathrm{He}$ advises doctors to ask every patient: "What would you most like to do, that your problem stops you from doing?" He reports that most patients are quite realistic in their replies. A 75 -year-old with emphysema is unlikely to say they want to win an Olympic medal in athletics, but they may cherish a hope of being able to go round the golf course in a buggy. Patients like these can become much better motivated if the doctor knows this and uses it to set objectives. I wish someone had taught me these question years ago.

Similarly, I have just learned how to modify one of my favourite questions: 'Is there anything else?' Apparently, the question is even more effective if you ask: 'Is there something else?' The slight change of wording gives people permission to say things that were on the tip of their tongue, but felt nervous about disclosing to the doctor. I learned one of the best questions from seeing an eminent cardiologist for myself. His consultation skills for the first 10 min of our encounter were terrible, but he then made eye contact for the first time and asked me one more question: "What else is it important for me to know about you?" It transformed the consultation.

I was a long way into my career before someone taught me the simplest rule of all about questions. If you ask a question beginning with a verb (eg, 'do you?' or 'can you?') you are probably asking a 'closed' question. In most cases, you will then get a short and uninformative answer. By contrast, if you make a habit of using words like 'what,' 'how' or 'when, you will find these are mostly 'open' questions. You 
will bring out fuller and more helpful answers. Starting a question with a tag like 'Supposing...' or 'What would need to happen...' are even better. If you start experimenting with techniques like these, and keep a record of what works for you and your patients, you may soon find that the most rewarding moments of the day are not just when you make a difficult diagnosis. They are also when patients suddenly stop to think and say: "Now, that's a really good question..."
Competing interests None.

Provenance and peer review Commissioned; internally peer reviewed.

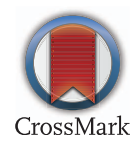

To cite Launer J. Postgrad Med J 2014;90:121-122.

Received 2 January 2014

Accepted 2 January 2014

Postgrad Med J 2014;90:121-122.

doi:10.1136/postgradmedj-2014-132565

\section{REFERENCES}

1 Ward H, Mehta G, Kovoor J, et al. Ask One Question! http://www.1000livesplus.wales.nhs.uk/opendoc/ 204619 (accessed 28 Dec 2013).

2 Rollnick S, Butler C, Kinnersley P, et al. Motivational interviewing. BMJ 2010;340:1242-5.

3 Penn P. Circular questioning. Fam Proc 1982;21:267-80.

4 Launer J. Narrative based supervision. In: Sommers L, Launer J. eds. Clinical uncertainty in primary care: the challenge of engagement. New York: Springer, 2013:147-61.

5 Cassell $\mathrm{E}$. The nature of healing: the modern practice of medicine. Oxford: Oxford University Press, 2012. 